\title{
A Comparative Study of Classification Algorithms using Data Mining: Crime and Accidents in Denver City the USA
}

\author{
Amit Gupta \\ School of Computing and Mathematics \\ Charles Sturt University \\ Melbourne, Victoria \\ Azeem Mohammad \\ School of Computing and Mathematics \\ Charles Sturt University \\ Melbourne, Victoria
}

\author{
Ali Syed \\ School of Computing and Mathematics \\ Charles Sturt University \\ Melbourne, Victoria \\ Malka N. Halgamuge \\ School of Computing and Mathematics \\ Charles Sturt University \\ Melbourne, Victoria
}

\begin{abstract}
In the last five years, crime and accidents rates have increased in many cities of America. The advancement of new technologies can also lead to criminal misuse. In order to reduce incidents, there is a need to understand and examine emerging patterns of criminal activities. This paper analyzed crime and accident datasets from Denver City, USA during 2011 to 2015 consisting of 372,392 instances of crime. The dataset is analyzed by using a number of Classification Algorithms. The aim of this study is to highlight trends of incidents that will in return help security agencies and police department to discover precautionary measures from prediction rates. The classification of algorithms used in this study is to assess trends and patterns that are assessed by BayesNet, NaiveBayes, J48, JRip, OneR and Decision Table. The output that has been used in this study, are correct classification, incorrect classification, True Positive Rate (TP), False Positive Rate (FP), Precision (P), Recall (R) and Fmeasure $(F)$. These outputs are captured by using two different test methods: k-fold cross-validation and percentage split. Outputs are then compared to understand the classifier performances. Our analysis illustrates that JRip has classified the highest number of correct classifications by $73.71 \%$ followed by decision table with $73.66 \%$ of correct predictions, whereas OneR produced the least number of correct predictions with $64.95 \%$. NaiveBayes took the least time of $0.57 \mathrm{sec}$ to build the model and perform classification when compared to all the classifiers. The classifier stands out producing better results among all the classification methods. This study would be helpful for security agencies and police department to discover data patterns and analyze trending criminal activity from prediction rates.
\end{abstract}

Keywords-Data Mining; Classification; Big Data; Crime and Accident

\section{INTRODUCTION}

Technologies provide companies new ways to gather talents of innovators working outside corporate margins. Corporate companies create real prosperity when they combine technology with new ways of doing business and storing data at a standard. There is a need to store data as the
Computer technology and the use of Internet has heightened the use of social media such as Facebook and Twitter. The increase in social media urges the need for collecting, storing and processing data for company's development. Analyzing this big data is a challenging process, and therefore the need for certain tools and techniques that are significant in sorting huge amounts of data becomes extremely important. Data Mining is one of the disciplines that is used to convert raw data into meaningful information and knowledge [1]. Data mining searches and analyses large quantities of data automatically by discovering, learning and knowing hidden patterns, trends, and structures [2] and it answers questions that cannot be addressed through simple query and reporting techniques [3]. Data Mining is broadly classified into two categories [4], Predictive Data Mining: that deals with the use of few attributes from a dataset and foretells the future value, or it could also be said that the developing model of the system as per given data. On the other hand, Descriptive Data Mining: finds patterns that describe the data, in other words, presenting new information based on the available dataset trends available.

With the use of new tools and techniques, the offenses and accidents are tracked, monitored and reduced; but at the same time, people are getting more knowledgeable about different crimes and ways to perform them with information available online at their fingertips. The use of technology such as surveillance cameras, speed detection devices, fire and burglary alarms, has helped various monitoring and tracking easier than ever. The types of software that are used today, stores huge amount of data that is collected every day [5]. A particular data set related to crimes and accidents from Denver city, USA has been obtained, and data mining techniques are applied to analyze and find information. The criminal activities and accidents show that there is an increase in death rates in the USA [6]. The major cause of road accidents is drink driving, over speed, carelessness, and the violation of traffic rules [5]. Assessing the cause of crimes is extremely important as it makes taking precarious measures easier. 
Education or informing police depends on these assessments. Additionally, the cause of these accidents is only preventable if they are tracked and evaluated to inform police in taking measures for minimizing it and bringing awareness to public. This paper is organized as follows. In Section II, we introduce the dataset and attributes in it, and how the data was collected and pre-processed. It also lists and explains the selected classification algorithms. Section III outlines the results obtained by using two different test methods and also the dataset is analyzed on different criteria's giving us insight on trends and patterns of incidents that have occurred in the due course. Section V concludes the paper.

\section{MATERIALS AND METHODS}

This paper has used the predictive method of data mining where the particular attribute value is predicted based on other related attributes. A few classification algorithms: BayesNet, NaiveBayes, OneR, J48, Decision Table and JRip are used in this paper to predict the outcomes of collected statistical data.

\section{A. Data Collection}

Data is collected from statistical websites: US City open data census and official government site of Denver city from the year 2011 to 2015, and this data is based on the National Incident-Based Reporting System (NIBRS) where the data is updated every day. This dataset excludes crimes related to child abuse and sexual assault as per legal restrictions law. This Dataset contains 15 attributes and 372,392 instances.

TABLE I. ATTRIBUTE DESCRIPTION FOR CLASSIFICATION

\begin{tabular}{|l|l|}
\hline Attribute Name & Description \\
\hline Incident-ID & $\begin{array}{l}\text { Unique identification number for a } \\
\text { particular incident. }\end{array}$ \\
\hline Offense-ID & $\begin{array}{l}\text { Unique identification number related to } \\
\text { particular Offense. }\end{array}$ \\
\hline Offense-Code & Code associated to each offense type \\
\hline Offense-TypeID & Different types of offenses \\
\hline Offence-CategoryID & $\begin{array}{l}\text { Offenses grouped / assigned into } \\
\text { categories. }\end{array}$ \\
\hline First-Occurrence-Date & Date incident first occurred on. \\
\hline Last-Occurrence-Date & Date incident last occurred on. \\
\hline Reported-Date & Date on which the incident was reported. \\
\hline Incident -Address & $\begin{array}{l}\text { Address of the location where an incident } \\
\text { happened. }\end{array}$ \\
\hline GeoX & Geographical location \\
\hline GeoY & Geographical location \\
\hline District-ID & $\begin{array}{l}\text { Name of the district where an incident took } \\
\text { place. }\end{array}$ \\
\hline Precinct-ID & Precinct name where an incident occurred. \\
\hline Neighbourhood-ID & Nearby location to the incident \\
\hline Incident Type & Type of incident (crime/accident) \\
\hline
\end{tabular}

\section{B. Data Pre-processing}

The raw data obtained does not give any information in the form it appears. The raw data stored could contain errors due to multiple reasons like, missing data, inconsistencies that arise due to merging data, incorrect data entry procedures, and so on [7]. Deriving meaningful information from the raw data requires preprocessing of data that converts real-time data into computer readable format. The phases involved in data processing are as shown in Fig. 1.

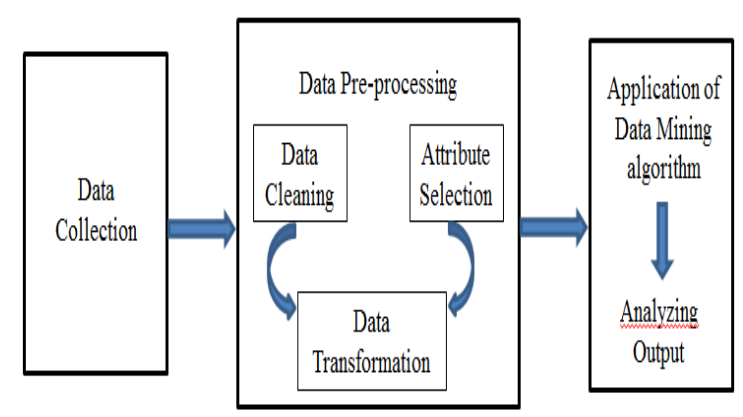

Fig. 1. Data processing of crime and accident dataset obtained for Denver City the USA

The preprocessing is an important phase in data mining. This stage involves the attribute selection, data cleaning, and data transformation [8]. This process starts off with data collection, then the required features or attributes have been selected from the raw data, ready for analysis. Then Data cleaning was performed by eliminating the errors and missing values, with the correction of syntaxes, for example, the address attributes. Finally, the data is prepared and transformed into a suitable and readable format for the datamining tool to generate.

\section{Classification Algorithms}

A number of classifications and algorithms are available, and few of them have been selected and used. Below table presents the method used and gives a brief description of the approach and how it is matched with the classifier. The classifiers that are selected are Bayesian, decision trees, and rules based which are outlined in Table 2 .

TABLE II. ClassificAtion METHOdS USED IN THIS STUdy AND DESCRIPTION OF THE METHODS

\begin{tabular}{|l|l|}
\hline Classifier & Description \\
\hline NaiveBayes & $\begin{array}{l}\text { This supervised learning algorithm is a probabilistic } \\
\text { classifier and uses statistical method for each } \\
\text { classification. }\end{array}$ \\
\hline J48 & $\begin{array}{l}\text { J48 is an algorithm that generates decision tree using } \\
\text { C4.5 algorithms an extension of ID3 algorithm and is } \\
\text { used for classification. }\end{array}$ \\
\hline JRip & $\begin{array}{l}\text { It implements a propositional rule learner called as } \\
\text { "Repeated Incremental Pruning to Produce Error } \\
\text { Reduction (RIPPER)" and uses sequential covering } \\
\text { algorithms for creating ordered rule lists. The } \\
\text { algorithm goes through 4 stages: Growing a rule, } \\
\text { Pruning, Optimization and Selection [9]. }\end{array}$ \\
\hline BayesNet & $\begin{array}{l}\text { Bayes Net model represents probabilistic relationships } \\
\text { among a set of random variables graphically. It models } \\
\text { the quantitative strength of the connections between } \\
\text { variables, allowing probabilistic beliefs about them to } \\
\text { be updated automatically as new information that } \\
\text { becomes available. It is a directed acyclic graph (DAG) } \\
\text { G that encodes a joint probability distribution, where } \\
\text { the nodes of graph represent random variable and arc } \\
\text { represent correlation between variables [10]. }\end{array}$ \\
\hline OneR & $\begin{array}{l}\text { A simple classification that produces one rule for each } \\
\text { predictor in the data and then the rule with smallest } \\
\text { total error is selected [11]. }\end{array}$ \\
\hline
\end{tabular}




\begin{tabular}{|l|l|}
\hline Decision Table & $\begin{array}{l}\text { Builds a simple decision table majority classifier. It } \\
\text { evaluates feature subsets using best-first search and can } \\
\text { use cross-validation for evaluation. }\end{array}$ \\
\hline
\end{tabular}

\section{Data Analysis}

This study deals with applying the stated classification algorithms in Table 2, to the crime and accident dataset obtained from Denver city, and compared the outputs/results of the classification methods. The analysis is performed based on varied outputs attained from identified number of correct instances and less execution time taken to build the model. The evaluation also helps to gain insights onto which incidents are high in number overall, during a given period of time, and how the trends have been for the last five years.

The software used for this analysis and application of algorithms is Weka (Waikato Environment for Knowledge Analysis, version 3.7). This software allows people to compare different machines to learn algorithms on datasets [11] that contain a collection of visualization tools and algorithms. It is useful for predictive modeling and analyzing data, along with graphical user interfaces for easy access to this functionality [12].

\section{RESULTS AND DISCUSSIONS}

Results obtained this study are based on different test options: k-fold cross-validation and percentage split criteria.

\section{A. Prediction: $k$-fold validation}

This study has used K-fold cross validation $(\mathrm{k}=10)$ method. This method runs the test 10 times, and the first 9 times is used for training, and the final fold is for testing [3] [13], and we have also used the percentage split approach for comparing the outputs and performance of used algorithms. Performances and outputs of each classifier method obtained are compared and presented in Table 3.

TABLE III. Classifiers ACCuRACy ON THE Dataset BASED ON 10Fold CROSS VALIDATION TEST MODE

\begin{tabular}{|l|l|l|}
\hline Classification Method & $\begin{array}{l}\text { Correctly } \\
\text { Classified } \\
\text { Incidents }\end{array}$ & $\begin{array}{l}\text { Incorrectly } \\
\text { Classified } \\
\text { Incidents }\end{array}$ \\
\hline NaiveBayes & $66.80 \%$ & $33.19 \%$ \\
\hline Bayes net & $68.74 \%$ & $31.25 \%$ \\
\hline J48 & $73.54 \%$ & $26.45 \%$ \\
\hline OneR & $64.95 \%$ & $35.04 \%$ \\
\hline Decision Table & $73.66 \%$ & $26.34 \%$ \\
\hline JRip & $73.71 \%$ & $26.28 \%$ \\
\hline
\end{tabular}

JRip classifier has identified a number of incidents correctly with $73.71 \%$, followed by Decision Table having correct classification rate of $73.66 \%$ compared to other classifiers and OneR has determined least correct instances with $64.95 \%$.

TABLE IV. ClassifiER EXECUTION TIME AND RoOT MEAN SQUARE ERROR ON THE DATASET BASED ON 10-FOLD CROSS VALIDATION TEST MODE

\begin{tabular}{|l|l|l|}
\hline Classification Method & $\begin{array}{l}\text { Time to Build the } \\
\text { Model } \\
\text { (Seconds) }\end{array}$ & $\begin{array}{l}\text { Root Mean } \\
\text { Squared Error }\end{array}$ \\
\hline NaiveBayes & 0.57 & 0.460 \\
\hline Bayes net & 4.34 & 0.461 \\
\hline
\end{tabular}

\begin{tabular}{|l|l|l|}
$\mathrm{J} 48$ & 0.87 & 0.440 \\
\hline OneR & 0.81 & 0.592 \\
\hline Decision Table & 18.6 & 0.435 \\
\hline JRip & 21.27 & 0.440 \\
\hline
\end{tabular}

Execution time is higher for JRip with $21.27 \mathrm{sec}$ and Decision Table with $18.6 \mathrm{sec}$, while NaiveBayes time to build the model was the least with $0.57 \mathrm{sec}$, with J48 and OneR time for a model build is $0.87 \mathrm{sec}$ and $0.81 \mathrm{sec}$, respectively.

There are different performances and measures that are calculated based on the confusion matrix produced by the algorithms. Fig. 2 portrays the model of confusion matrix also known as contingency table. In this matrix, each row exhibits the actual class and column exhibits the predicted class [11].

\section{Predicted Class}

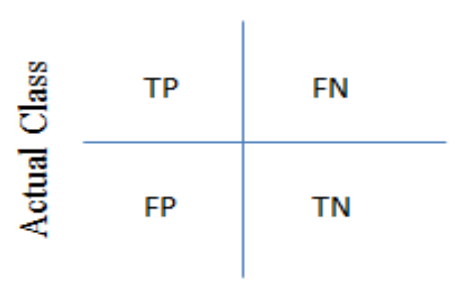

Fig. 2. Confusion Matrix representation

TP (True Positive) and TN (True negatives) are instances correctly classified as a given class and FP (False Positive) and FN (False Negative) are the instances falsely classified as a given class. Other measures are: Precision - \% of selected items that are correct and are calculated as Precision $(\mathrm{P})=\mathrm{TP} /$ $(\mathrm{TP}+\mathrm{FP})$ and Recall - \% of correct items that are selected and the calculation for it is Recall $(\mathrm{R})=\mathrm{TP} /(\mathrm{TP}+\mathrm{FN})$ [14]. With the help of Precision and Recall is calculated F-Measure $(\mathrm{F})$ the Harmonic mean of precision and recall, calculated as $\mathrm{F}=2 * \mathrm{R} * \mathrm{P} /(\mathrm{R}+\mathrm{P})$.

TABle V. Performance Measures Calculated Based on CONFUSION MATRIX USING 10-FOLD CROSS VALIDATION

\begin{tabular}{|l|l|l|l|l|l|}
\hline Classifier & TP Rate & FP Rate & $\begin{array}{l}\text { Precision } \\
(\mathbf{P})\end{array}$ & $\begin{array}{l}\text { Recall } \\
(\mathbf{R})\end{array}$ & $\begin{array}{l}\text { F- } \\
\text { Measure } \\
(\mathbf{F})\end{array}$ \\
\hline NaiveBayes & $66.80 \%$ & $53.30 \%$ & $66.50 \%$ & $66.80 \%$ & $66.60 \%$ \\
\hline Bayes net & $68.70 \%$ & $55.20 \%$ & $66.90 \%$ & $68.70 \%$ & $67.70 \%$ \\
\hline J48 & $73.60 \%$ & $73.60 \%$ & $54.20 \%$ & $73.60 \%$ & $62.50 \%$ \\
\hline OneR & $65.00 \%$ & $12.50 \%$ & $85.00 \%$ & $65.00 \%$ & $66.50 \%$ \\
\hline Decision Table & $73.70 \%$ & $73.30 \%$ & $68.10 \%$ & $73.70 \%$ & $62.70 \%$ \\
\hline JRip & $73.70 \%$ & $73.10 \%$ & $70.50 \%$ & $73.70 \%$ & $62.90 \%$ \\
\hline
\end{tabular}

Above Table 5 shows the TP and FP rate of each classifier, the weighted average of Precision, Recall and F-Measure, obtained by using the 10-fold cross-validation approach.

Decision Table and JRip have the highest TP Rate (True Positive) by $73.7 \%$ and Recall values $73.7 \%$, followed by $\mathrm{J} 48$ having TP rate and recall value of $73.6 \%$. OneR has greater precision when compared to other algorithms.

\section{B. Prediction: Percentage Split}

Another test option of split criteria available is also used to compare and evaluate the classifier outputs. In the percentage split method, the algorithm is trained in a certain percentage of 
data first, and then the learning is tested on the remainder of the data. Table 6 presents the result of classifier output based on split criteria.

TABLE VI. RESUlt OF ClASSIFIER ACCURACy BASED ON SPLIT CRITERION TEST MODE

\begin{tabular}{|c|c|c|c|c|}
\hline Classifier & $\begin{array}{l}\text { Train } \\
\text { Data } \\
(\%)\end{array}$ & $\begin{array}{l}\text { Test } \\
\text { Data } \\
(\%)\end{array}$ & $\begin{array}{l}\text { Correctly } \\
\text { Classified } \\
(\%)\end{array}$ & $\begin{array}{l}\text { Incorrectly } \\
\text { Classified (\%) }\end{array}$ \\
\hline \multirow{9}{*}{ BayesNet } & 90 & 10 & 79.53 & 20.46 \\
\hline & 80 & 20 & 78.59 & 21.40 \\
\hline & 70 & 30 & 77.63 & 22.36 \\
\hline & 60 & 40 & 76.79 & 23.20 \\
\hline & 50 & 50 & 75.81 & 24.18 \\
\hline & 40 & 60 & 74.63 & 25.36 \\
\hline & 30 & 70 & 73.29 & 26.70 \\
\hline & 20 & 80 & 72.42 & 27.57 \\
\hline & 10 & 90 & 72.00 & 27.99 \\
\hline & & & & \\
\hline \multirow{9}{*}{ NaiveBayes } & 90 & 10 & 75.85 & 24.14 \\
\hline & 80 & 20 & 76.18 & 23.81 \\
\hline & 70 & 30 & 61.77 & 38.22 \\
\hline & 60 & 40 & 61.92 & 38.07 \\
\hline & 50 & 50 & 66.03 & 33.96 \\
\hline & 40 & 60 & 61.48 & 38.51 \\
\hline & 30 & 70 & 68.33 & 31.66 \\
\hline & 20 & 80 & 30.04 & 69.95 \\
\hline & 10 & 90 & 30.90 & 60.09 \\
\hline \multirow{9}{*}{ OneR } & 90 & 10 & 65.07 & 64.92 \\
\hline & 80 & 20 & $\begin{array}{l}05.01 \\
63.02\end{array}$ & $\begin{array}{l}04.92 \\
36.97\end{array}$ \\
\hline & 70 & 30 & 60.68 & 39.31 \\
\hline & 60 & 40 & 57.92 & 42.07 \\
\hline & 50 & 50 & 55.11 & 44.88 \\
\hline & 40 & 60 & 51.40 & 48.59 \\
\hline & 30 & 70 & 47.24 & 52.75 \\
\hline & 20 & 80 & 41.93 & 58.06 \\
\hline & 10 & 90 & 35.14 & 65.85 \\
\hline & & & & \\
\hline \multirow{9}{*}{$\mathrm{J} 48$} & 90 & 10 & 73.61 & 26.38 \\
\hline & 80 & 20 & 73.67 & 26.32 \\
\hline & 70 & 30 & 73.62 & 26.37 \\
\hline & 60 & 40 & 73.71 & 26.28 \\
\hline & 50 & 50 & 73.68 & 26.31 \\
\hline & 40 & 60 & 73.70 & 26.29 \\
\hline & 30 & 70 & 73.61 & 26.38 \\
\hline & 20 & 80 & 73.61 & 26.38 \\
\hline & 10 & 90 & 73.64 & 26.35 \\
\hline
\end{tabular}

Figures 3, 4, 5 and 6 demonstrate the graphical representation of the corresponding classifier output. Figures 3, 4 and 5 indicate Bayes net, NaiveBayes and OneR perform identically. When the percentage of data tested is less the results are more accurate. As the amount of test data increases the percentage of correct classification decreases as a result. This is because a number of data samples trained are less. As seen from Fig 6 it shows that J48 has correctly classified the higher number of instances when the test and trained data is almost equal, and lowest classification rate are when test data is either least or most.

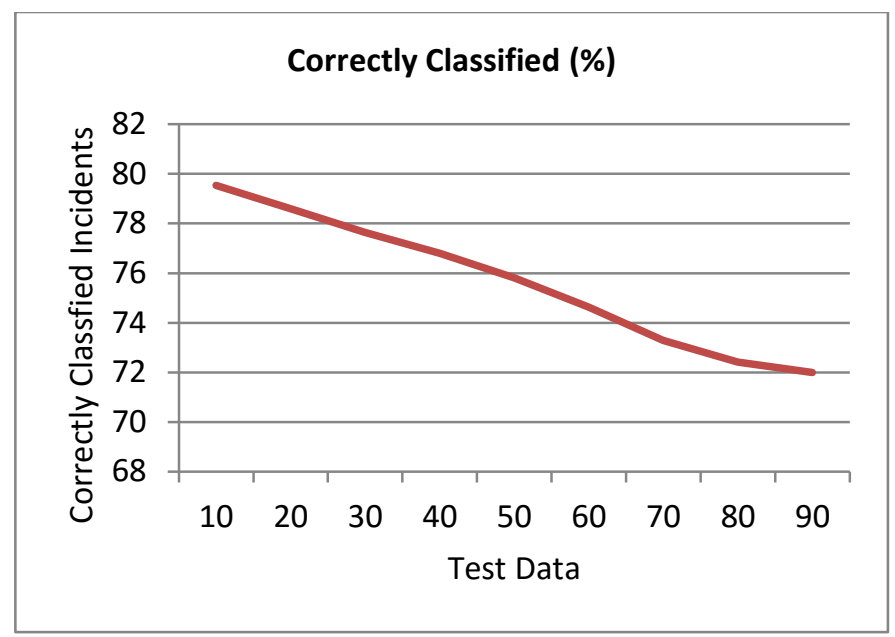

Fig. 3. Bayes net Classification using split percentage test option

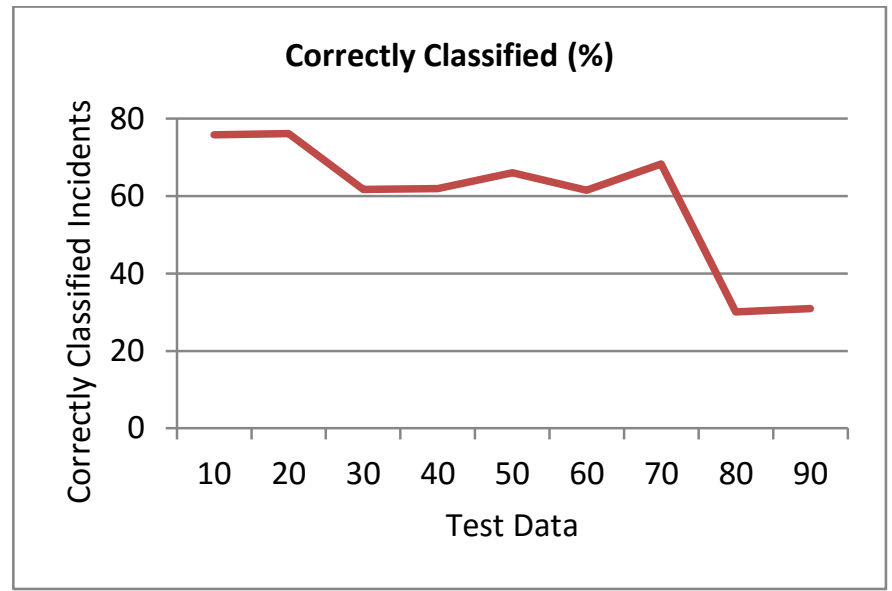

Fig. 4. NaiveBayes Classification using split percentage test option

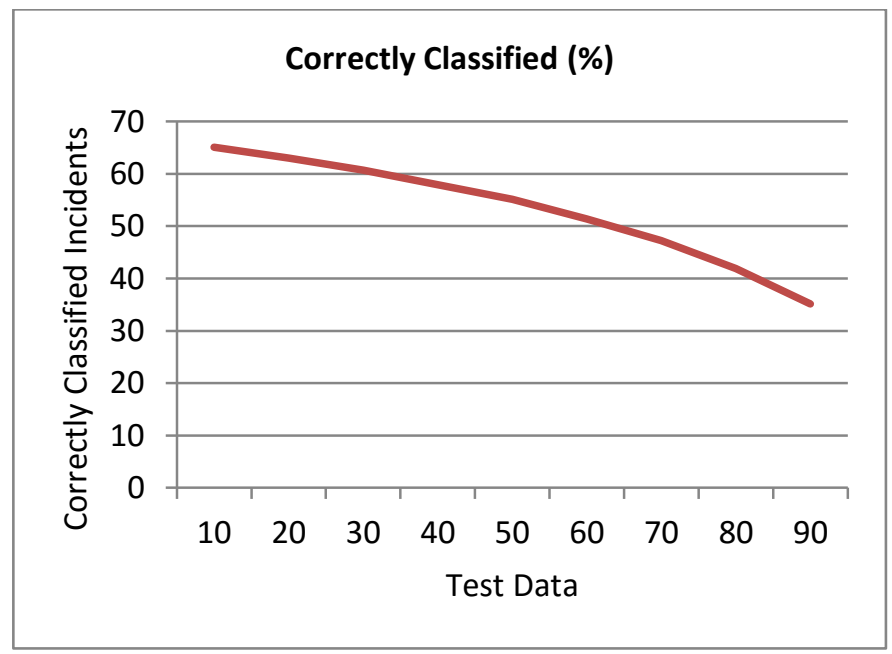

Fig. 5. OneR Classification using split percentage test option 


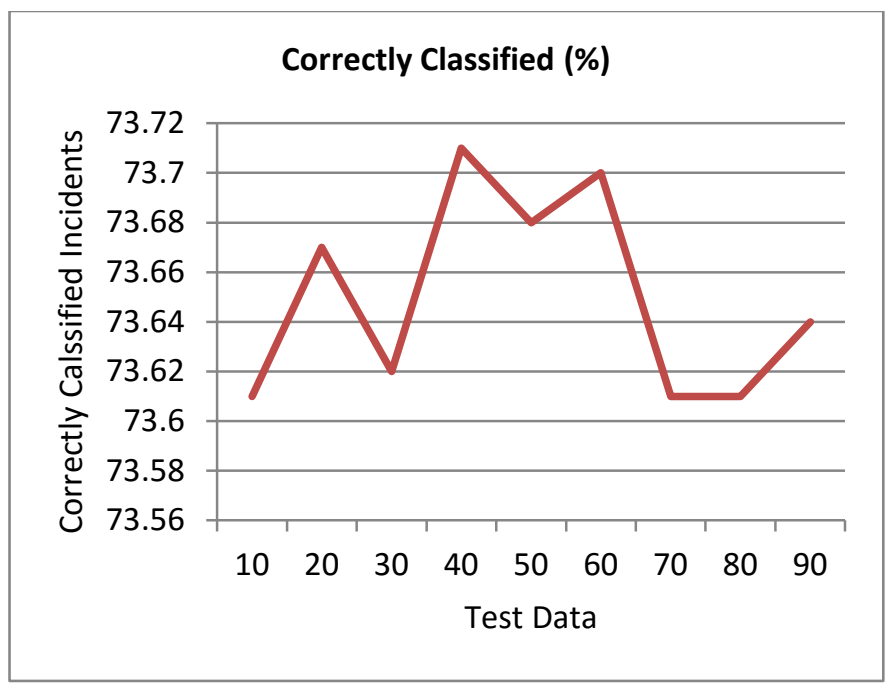

Fig. 6. J48 Classification using split percentage test option

Further analysis of data is performed based on different criteria's.

TABLE VII. CRIME AND ACCIDENT ON WEEKDAY/WEEKEND

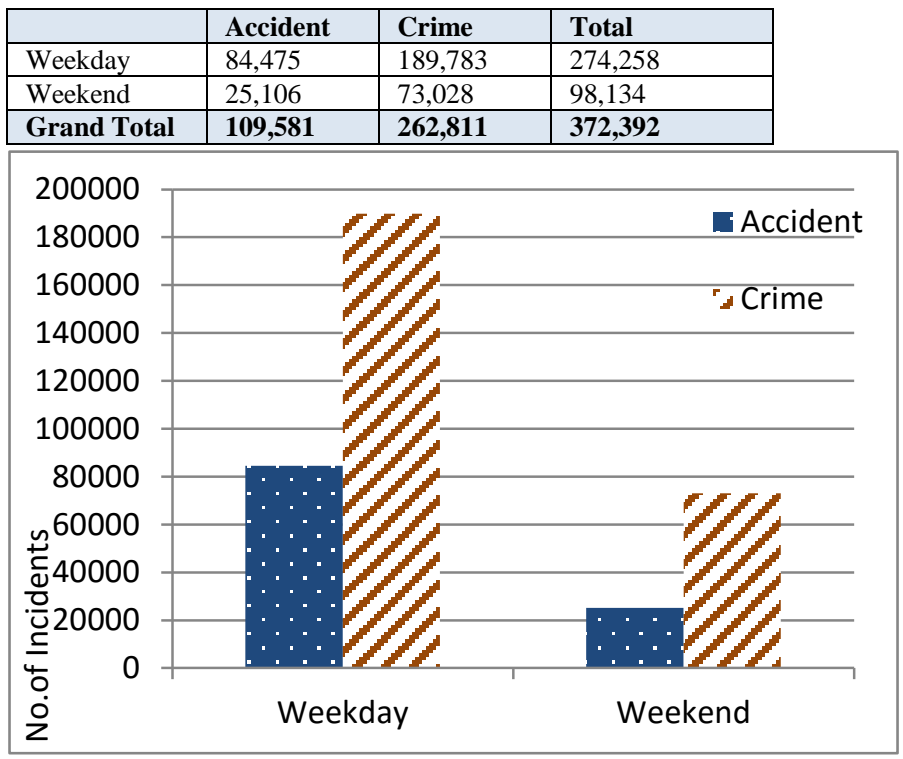

Fig. 7. Crime and accident based on weekday and weekend

TABLE VIII. COUNT OF INCIDENTS ON A MONTHLY BASIS

\begin{tabular}{|l|l|l|l|}
\hline Month & Crime & Accident & Total \\
\hline January & 24,364 & 10,525 & 34,889 \\
\hline February & 20,904 & 10,004 & 30,908 \\
\hline March & 22,010 & 8927 & 30,937 \\
\hline April & 19,018 & 8186 & 27,204 \\
\hline May & 20,935 & 8708 & 29,643 \\
\hline June & 22,085 & 8781 & 30,866 \\
\hline July & 23,951 & 8887 & 32,838 \\
\hline August & 24,322 & 9306 & 33,628 \\
\hline September & 22,833 & 9203 & 32,036 \\
\hline October & 22,477 & 9345 & 31,822 \\
\hline November & 20,193 & 8528 & 28,721 \\
\hline December & 19,719 & 9181 & 28,900 \\
\hline Grand Total & $\mathbf{2 6 2 , 8 1 1}$ & $\mathbf{1 0 9 , 5 8 1}$ & $\mathbf{3 7 2 , 3 9 2}$ \\
\hline
\end{tabular}



Fig. 8. Count of crime and accidents on a monthly basis

Figure 8 indicates that crime and accidents are more likely to occur during the months of January and February. This is because people start their daily routines after a long vacation of Christmas and New Year. As a result, more public is out in the traffic as people commute and drive to, schools, offices, and work. The trends show an increase of incidents that occur during July and August, as this is the start of the academic year for schools and colleges. During this time, accidents are $60 \%$ lower on the weekends when compared to weekdays due to less traffic and crowd on roads. Crime is $60 \%$ less on the weekends, as most people stay home relaxing; therefore, crimes such as murder, burglary, and robbery are less likely to occur.

TABLE IX. YeAR-Wise PRESENTATION OF CRIME AND ACCIDENTS

\begin{tabular}{|l|l|l|l|}
\hline Year & Accident & Crime & Total \\
\hline 2011 & 20,722 & 36,419 & 57,141 \\
\hline 2012 & 19,398 & 36,258 & 55,656 \\
\hline 2013 & 19,588 & 51,820 & 71,408 \\
\hline 2014 & 21,914 & 61,340 & 83,254 \\
\hline 2015 & 23,245 & 63,632 & 86,877 \\
\hline 2016 & 4714 & 13,342 & 18,056 \\
\hline Total & $\mathbf{1 0 9 , 5 8 1}$ & $\mathbf{2 6 2 , 8 1 1}$ & $\mathbf{3 7 2 , 3 9 2}$ \\
\hline
\end{tabular}

TABLE X. TYPES OF OFFENSES

\begin{tabular}{|l|l|}
\hline Offense Type & $\begin{array}{l}\text { No. of } \\
\text { Offenses }\end{array}$ \\
\hline Murder & 210 \\
\hline Arson & 533 \\
\hline White-collar-crime & 5299 \\
\hline Robbery & 5908 \\
\hline Aggravated-assault & 8030 \\
\hline Other-crimes-against-persons & 13,544 \\
\hline Auto-theft & 19,271 \\
\hline Drug-alcohol & 21,488 \\
\hline Burglary & 24,571 \\
\hline Theft-from-motor-vehicle & 32,998 \\
\hline Larceny & 40,737 \\
\hline Public-disorder & 41,712 \\
\hline All-other-crimes & 48,510 \\
\hline Total & $\mathbf{3 7 2 , 3 9 2}$ \\
\hline
\end{tabular}






Fig. 9. Number of crime and accidents identified year-wise

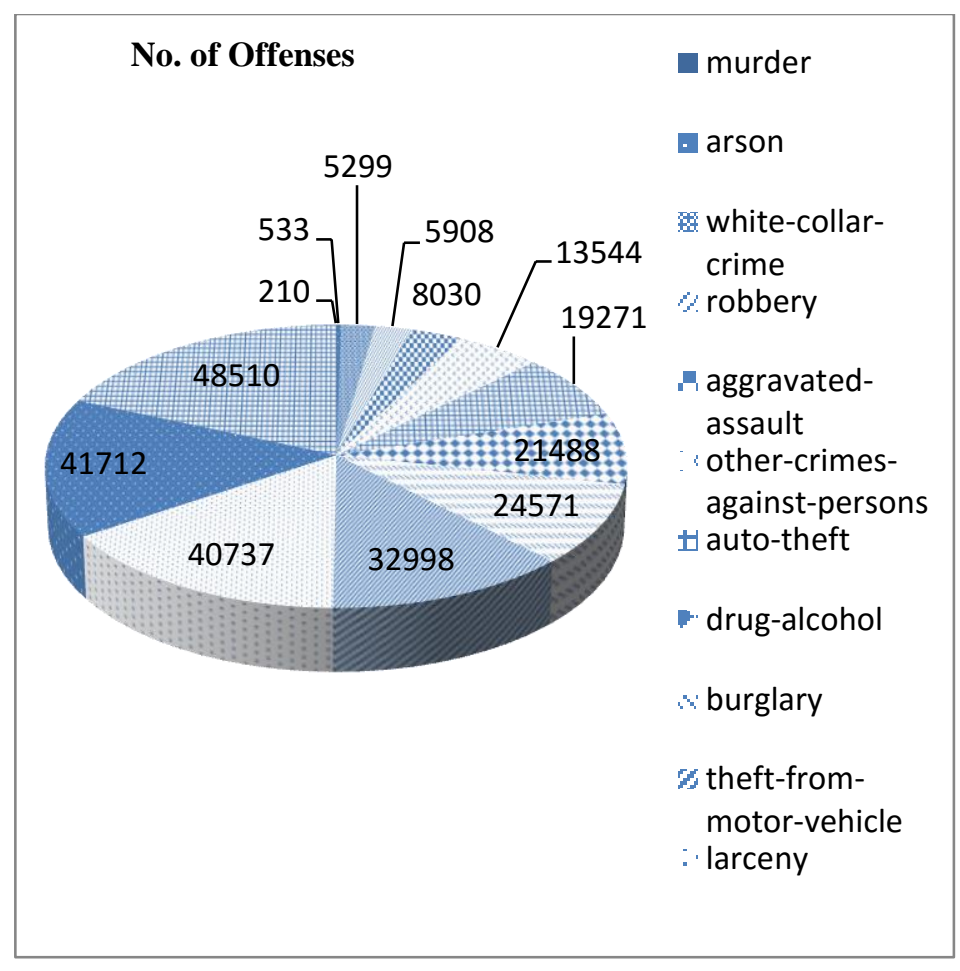

Fig. 10. Different types of offenses indicating number of incidents in each category

TABLE XI. COUNT OF INCIDENTS YEAR-Wise IN EACH OFFENSE TyPE

\begin{tabular}{|l|l|l|l|l|l|l|l|}
\hline Offense Category & $\mathbf{2 0 1 1}$ & $\mathbf{2 0 1 2}$ & $\mathbf{2 0 1 3}$ & $\mathbf{2 0 1 4}$ & $\mathbf{2 0 1 5}$ & $\mathbf{2 0 1 6}$ & Total \\
\hline Aggravated-assault & 1314 & 1467 & 1522 & 1599 & 1755 & 373 & 8030 \\
\hline All-other-crimes & 1843 & 1986 & 9920 & 15,491 & 15,589 & 3681 & 48,510 \\
\hline Arson & 92 & 92 & 95 & 130 & 107 & 17 & 533 \\
\hline Auto-theft & 3545 & 3421 & 3383 & 3514 & 4460 & 948 & 19,271 \\
\hline Burglary & 4698 & 4711 & 4800 & 4553 & 4836 & 973 & 24,571 \\
\hline Drug-alcohol & 1416 & 1714 & 4784 & 6061 & 6153 & 1360 & 21,488 \\
\hline Larceny & 5959 & 6691 & 8350 & 9336 & 8778 & 1623 & 40,737 \\
\hline Murder & 41 & 33 & 39 & 33 & 55 & 9 & 210 \\
\hline $\begin{array}{l}\text { Other-crimes-Against- } \\
\text { persons }\end{array}$ & 1286 & 1427 & 2617 & 3649 & 3840 & 725 & 13,544 \\
\hline Public-disorder & 6454 & 5948 & 8195 & 9728 & 9400 & 1987 & 41,712 \\
\hline Robbery & 1133 & 1212 & 1058 & 1072 & 1188 & 245 & 5908 \\
\hline $\begin{array}{l}\text { Theft-from-motor- } \\
\text { vehicle }\end{array}$ & 7575 & 6632 & 6222 & 5129 & 6226 & 1214 & 32,998 \\
\hline Traffic-accident & 20,722 & 19,398 & 19,588 & 21,914 & 23,245 & 4714 & 109,581 \\
\hline White-collar-crime & 1063 & 924 & 835 & 1045 & 1245 & 187 & 5299 \\
\hline Total & $\mathbf{5 7 , 1 4 1}$ & $\mathbf{5 5 , 6 5 6}$ & $\mathbf{7 1 , 4 0 8}$ & $\mathbf{8 3 , 2 5 4}$ & $\mathbf{8 6 , 8 7 7}$ & $\mathbf{1 8 , 0 5 6}$ & $\mathbf{3 7 2 , 3 9 2}$ \\
\hline
\end{tabular}






Fig. 11. Number of incidents occurring in each category of offense year-wise

Above Figure 11 shows that drug and alcohol consumption has been increasing year-by-year. In the year 2009, marijuana was legalized in many states of the US, it was allowed on the basis of certain medical conditions. However after a couple of years, it was legalized in Colorado as well. This legalization in 2012 has made the availability of it easier and since then the intake of this drug has been increasing continuously [15]. It is evident from the analysis results as per Fig. 11 from the year 2012-2013 there has been more than 100\% increase in drug and alcohol consumption, nevertheless, no strong evidence has found that people consume marijuana truly for medical reasons.

\section{CONCLUSION}

Data Mining techniques and tools have brought tremendous change in the way data is analyzed revealing useful information. This paper has analyzed the application and performance of six classification algorithms that produce different results. Different test methods were used to predict the outcomes for same classification methods. This study has found that various crime patterns have heightened in particular seasons. Results obtained for various classification methods show different outputs and performance measures. Our analysis indicates JRip and Decision Table classified the most number of correct incidents with $73.71 \%$ and $73.66 \%$, whereas OneR classified showed the least number of correct incidents with $64.95 \%$. Although JRip is the most accurate classifier, it took the maximum time building the model with $21.2 \mathrm{sec}$. NaiveBayes model builds the quickest time with 0.57 sec. This study is helpful for various agencies, police department and other organizations aiding them to foresee prediction rate of incidents and develop strategies, plans, and preventive measures for the purpose of crime reduction.

\section{REFERENCES}

[1] J. H. Trevor, R. J. Tibshirani and J. H. Friedman, The elements of statistical learning: data mining, inference, and prediction. Springer, 2011.

[2] C. C. Aggarwal, Data Mining: The Textbook. Springer, 2015.

[3] R. A. El-Deen Ahmeda, M. E. Shehaba, S. Morsya and N. Mekawiea, Performance Study of Classification Algorithms for Consumer Online Shopping Attitudes and Behavior Using Data Mining. InCommunication Systems and Network Technologies (CSNT), 2015 Fifth International Conference on IEEE, pp. 1344-1349.

[4] S. Gnanapriya, R. Suganya, G. S. Devi and M. S. Kumar, Data Mining Concepts and Techniques. Data Mining and Knowledge Engineering, vol. 2, p. 256-263, 2010.

[5] K. B. Saran and G. Sreelekha, Traffic video surveillance: Vehicle detection and classification. In 2015 International Conference on Control Communication \& Computing India (ICCC) IEEE, pp. 516-521, November 2015.

[6] P. C. Kratcoski and M. Edelbacher, "Collaborative Policing: Police, Academics, Professionals, and Communities Working Together for Education, Training, and Program Implementation", CRC Press: 2015, vol. 25.

[7] S. García, J. Luengo and F. Herrera, Data preprocessing in data mining. Switzerland: Springer, 2015.

[8] R. Deb, A. W. C. Liew, Incorrect attribute value detection for traffic accident data. In Neural Networks (IJCNN), 2015 International Joint Conference IEEE, 2015, pp. 1-7.

[9] V. Veeralakshmi and D. Ramyachitra, Ripple Down Rule learner (RIDOR) Classifier for IRIS Dataset. Issues, vol 1, p. 79-85.

[10] Bayes Nets. Retrieved from http://www.bayesnets.com/

[11] I. H. Witten, E. Frank and M. A. Hall, Data Mining: Practical machine learning tools and techniques, 3rd ed., Morgan Kaufmann, 2011.

[12] S. Kalmegh, Analysis of WEKA Data Mining Algorithm REPTree, Simple Cart and RandomTree for Classification of Indian News, February 2015.

[13] C. Sitaula, "A Comparative Study of Data Mining Algorithms for Classification. Journal of Computer Science and Control System"s, vol. $7,29$. 
[14] A. H. M. Ragab, A. Y. Noaman, A. S. Al-Ghamdi and A. I. Madbouly, A comparative analysis of classification algorithms for students college enrolment approval using data mining. In Proceedings of the 2014 Workshop on InteractionDesign in Educational Environments, 2014, ACM, p. 106.
[15] J. Schuermeyer, S. Salomonsen-Sautel, R. K. Price, S. Balan, C. Thurstone, S. J. Min and J. T. Sakai, Temporal trends in marijuana attitudes, availability and use in Colorado compared to nonmedical marijuana states: 2003-11. Drug and alcohol dependence, 2014, vol 140, p. 145-155. 